\title{
Economic Crisis in Greek ORs
}

\author{
Kostantinia Karathanasi*, Maria Malliarou\#, John Koutelekos*, Pavlos Sarafis*, \\ Panagiotis Prezerakos*
}

Department of Nursing, Technological Institution of Thessaly, Thessaly, Greece

Email: "

Received 1 October 2015; accepted 16 October 2015; published 22 October 2015

Copyright (C) 2015 by authors and OALib.

This work is licensed under the Creative Commons Attribution International License (CC BY).

http://creativecommons.org/licenses/by/4.0/

(c) (i) Open Access

\begin{abstract}
Greece's economic crisis has deepened despite the measures taken by the international community in 2010. The Greek economy shrank by $20 \%$ between 2008 and 2012 without evidence of growth in 2014. The unemployment was $24.3 \%$ in 2012 (7.7\% in 2008) and now the maximum rate of long-term unemployment went up to $14.4 \%$ [1]. The growing pressure from the Greek governments especially the hospitals budget cuts creates pressure on the effectiveness and efficiency, devastating the Greek healthcare system. Economic crisis in combination with the continuous growth of hospital costs services on one hand and the pressure by patients themselves for lower cost and better treatment on the other, has driven governments in Greece, to restructure the hospital sector (known as "hospital mergers").
\end{abstract}

\section{Keywords}

Operating Room, Healthcare System, Hospital Cost, Austerity, Economic, Crisis, Greece

Subject Areas: Economics

\section{Introduction}

Greece's economic crisis has deepened despite the measures taken by the international community in 2010. The Greek government-debt crisis started in late 2009 later referred to collectively as the European debt crisis. The Greek economy shrank by 20\% between 2008 and 2012 without evidence of growth in 2014. The unemployment was $24.3 \%$ in 2012 (7.7\% in 2008) and now the maximum rate of long-term unemployment went up to $14.4 \%$ [1]. The growing pressure from the Greek governments especially the hospitals budget cuts creates pressure on the effectiveness and efficiency, devastating the Greek healthcare system.

Economic crisis in combination with the continuous growth of hospital costs services on one hand and the pressure by patients themselves for lower cost and better treatment on the other, has driven governments in

"Kostantinia Karathanasi: Greek Army Officer; John Koutelekos: President of Greek Operating Room Nurses Association; Pavlos Sarafis: Assistant Professor of Cyprus University of Technology; Panagiotis Prezerakos: Professor of University of Peloponnese.

"Corresponding author. 
Greece, to restructure the hospital sector (known as "hospital mergers").

Many public hospitals faced intense deficit problems mainly caused by four factors:

- lack of incentives for staying within their budgets;

- reimbursement tardiness by social insurance companies;

- highly reduced hospital services compared to the actual per diem costs;

- free of charge services to all immigrants and poor people without any income.

Moreover, the healthcare system faces difficulties due to three main reasons:

- Lower profit due to the lower prices of the pharmaceutical products;

- Dept of Greek National Health System;

- A newly created National Organization for Providing Health Services (EOPYY) which will merge all the sickness funds together.

The pursuit of the central government to lower public spending by 3.4 billion $€$ (medication and supplies), i.e. about $15 \%$ of public expenditure, caused a dramatic reduction in supply. The Greek government reduced the health care cost by €4.5 billion in 3 years (from $€ 14$ billion - $\$ 18.4$ billion in 2009 to $€ 9.5$ billion in 2012). As a result rural areas faced grade difficulties and had to cope with the growing shortages of medicines and medical equipment [1] [2].

Additionally the curving of hospital budgets by $40 \%$, brought a dramatic reduction in medications supplies and caused immense staff shortages that led to a challenge in the care of surgical patients, to continue providing high-quality surgical care at a reduced cost [3].

\subsection{Statement of Purpose}

The purpose of this study, which was conducted under the auspices of Greek Operating Room Nurses Association (GORNA), was to identify how Greek OR nurses, dealt with problems due to economic austerity.

\subsection{Research Questions}

The addressed questions in this study were:

1) how economic austerity and cost-cutting have been dealt by Greek OR nurses?

2) what measures Greek OR nurses took in order to tackle economic austerity?

3) participants' optimism on how they deal with economic austerity was correlated with some demographics and occupational characteristics such as gender, educational level, type of Hospital.

\subsection{Statement of Significance to Nursing}

Economic crisis can be "used" as an opportunity to modify health policies, in order to provide cost-effectively and efficiently services by measures that will smooth the negative impact of financial shortages.

\section{Literature Review}

After a review of national and international researches in electronic databases such as PubMed and Scopus, using keywords economic crisis, health implications and operating room, the most apparent conclusion that came up, was that worldwide, healthcare systems have been under increasing pressure in order to improve performance, maintain quality and reduce cost at the same time. This has become particularly important after the outbreak of the recent economic crisis, which has led to tightening public budgets that have also affected healthcare [4].

The financial deteriorations led governments to take measures in order to cut down public expenses, such as public health care services, so to reduce the running cost and control their expenses. Certain numbers of studies have shown a conjunction between less nursing staff and higher rates of adverse patient complications, pointing the risk in safety and quality of health care. Other studies also support the fact that economic downturns affect overall health, highlighting major points such as the public spending of health care system, the quality of provided health services and the role restructuring of the health care personnel [5].

In Greece, the hospital income depends on central authorities that set the prices for care, the fees for medical treatment and the subsidies to the hospitals. However the increasing pressure by the governments, the insurance companies and patients themselves for cost reduction and quality treatment, led to the optimization of costeffectiveness. Thus the available resources distributed among the hospitals based to their effectiveness [6] [7]. 
In general the public-sector hospitals are funded by the state budget in $74 \%$, by fees in $13 \%$, and by private or other sources in $13 \%$. A correlation of revenue and expenditure reveals that the greater part of hospital supplies and all staff expenses are met by the state budget, while fees are sufficient only for food services, pharmaceuticals and other running costs (general expenses such as rent, transportations, electricity, water, telephones, cleaning, etc.). The functioning of those public hospitals cost 268 million drachmas of which only about $13 \%$ comprised by net revenues (hospitalization charges). Regarding staff salaries, doctors' part constitute $43 \%$ of the total cost, when nursing staff compose $31 \%$ and administrative staff the rest $26 \%$. Normally, in 2001 the daily cost of a public hospital was about 50,000 drachmas (1 USD $=190.6$ drachmas) [6].

Unfortunately planning and programming budget systems are not yet adopted by the Greek public hospitals. The year's budget is prepared according to former one, with the adjustment of the anticipated inflation rate.

On January 5, 2011 the Greek Minister of Health announced that hospital sector will be restructured, reorganized, with the aim of lowering the total costs of the services they provide, by merging hospitals. Hospital merges captured the public eye and became the center piece of health policy reform at the time of serious fiscal and debt crisis faced by Greece during the last two years. The reason why health has been targeted is the fact that Greece at the end of the previous decade came to spend about 10\% of GDP [OECD Health Data, 2011] and at the same time it has been widely published that corruption, under-the-table payments and tax evasion are rampant [8] [9]. The Greek health system before crisis was costly and inconsistent with what could finance, underfunded by the State in relation to Developed Countries, ineffective and inefficient in economic terms, with low efficiency of Social Expenditure, with intense overconsumption and provoked demand, inefficient allocation of human resources and finally with not satisfied users.

\section{Description of Study Design, Setting, Sample, Sampling Technique}

A non-experimental descriptive study conducted under the auspices of GORNA, on nurses working in Greek Ors.

\subsection{Description of Procedures for Protection of Participants' Rights}

Ethical issues: All participants completed the questionnaire and gave their permission to use it. Personally identifiable information was not collected from the participants, ensuring the results were anonymous. IRB was obtained by hospital scientific board.

\subsection{Description of Study Procedures/Methods}

\subsubsection{The Instrument}

The instrument was divided into two parts. The first part was designed to collect demographic data (i.e. gender, age, hospital, years of experience, educational level, number of procedures). The second part include a 19 items questionnaire, where the respondents give opinion on a 5 point Likert scale (from extremely to not at all) on how the economic crisis affected everyday practice in OR. Content validity was assured by 4 OR head nurses to whom the questionnaire had been provided and they were asked to provide feedback on how well each question was measured. Their feedback was then analyzed and informed decisions were made about the effectiveness of each question. Pilot study procedure was done to improve the internal validity. Reliability was calculated by the coefficient Cronbach (a) and for this current study only was found to be 0.71 .

\subsubsection{The Sample, Sampling Technique}

A convenience sample of 227 Greek OR Nurses working in public, private and army hospitals, participated in the study, voluntarily and anonymously. 250 questionnaires were distributed by a researcher who interviewed participants and finally 227 questionnaires were fully completed $(R R=90.8 \%)$. Convenience sampling technique is preferred because it is fast, inexpensive, easy and the subjects are readily available. Completion of the instrument took approximately 10 - 15 minutes, and no compensation was provided to the participants.

\subsection{Analysis}

Upon the collection of the questionnaires they were reviewed for completeness and then Statistical Package for the Social Sciences (SPSS version 19.0) has been used for the statistical analysis, to calculate mean score (M), 
standard deviation (SD) and variances were analyzed with $\chi^{2}$ test. P-value $\leq 0.05$ considered as statistical significant.

\section{Results}

From the 227 respondents, the 192 were women and 33 men. 63.3\% of them were married. The mean age of the respondents was $40.73(\mathrm{SD} \pm 7.124)$ years and the mean age of their work experience was 17.38 years (SD \pm 8.262). The majority of OR nurses were Registered Nurses $(73 \%, n=163)$ in Operating Rooms. Most of the respondents were working in public hospitals and only 7\% were in army hospitals (Table 1).

One of the first results was that most of respondents (33\%) answered that they were a little bit optimistic about crisis when $49 \%$ also felt quite a bit stressed about the crisis. $49 \%$ of the respondents saw their judgment quite a bit changed after the crisis and most of the respondents (53\%) believed that the State continues to quite a bit support health as a social commodity (Table 2).

Despite the fact that economic crisis moderately affect nursing staff (30\%), it does increase (50\% quite a bit) and prolong workload (moderately $=35 \%$ ) when at the same time (as it was expected) the amount of surgical procedures did not had any reduction ( $34 \%$ = not at all) except the costly ones ( $32 \%$ was the "quite a bit" answer) (Table 3).

A very optimistic result was that economic crisis had a positive impact in waste reduction (43\% answered "quite a bit") and $42 \%$ believe that there was also quite a bit reduction of materials needed in procedures. $44 \%$ of OR nurses were moderately satisfied on the quality of the materials upon the implementation of financial contents, but $38 \%$ believe that the quality of materials had quite a bit decreased. Also $27 \%$ of the respondents

Table 1. Type of hospital.

\begin{tabular}{ccc}
\hline Type of hospital & $\mathrm{n}$ & $\%$ \\
\hline Public & 166 & $73 \%$ \\
Private & 46 & 20 \\
Army & 15 & $7 \%$ \\
\hline
\end{tabular}

Table 2. Descriptive results of certain questions about nurses optimism and economic crisis.

\begin{tabular}{|c|c|c|c|c|c|c|c|c|c|c|}
\hline \multirow[b]{2}{*}{$\begin{array}{l}\text { OPTIMISTIC ABOUT ECONOMIC } \\
\text { CRISIS }\end{array}$} & \multicolumn{2}{|c|}{ NOT AT ALL } & \multicolumn{2}{|c|}{ A LITTLE BIT } & \multicolumn{2}{|c|}{ MODERATELY } & \multicolumn{2}{|c|}{ QUITE A BIT } & \multicolumn{2}{|c|}{ EXTREMELY } \\
\hline & 50 & $22 \%$ & 76 & $33.5 \%$ & 69 & $30.4 \%$ & 29 & $12.8 \%$ & 3 & $1.3 \%$ \\
\hline $\begin{array}{l}\text { DO YOU FEEL STRESS BECAUSE } \\
\text { OF ECONOMIC CRISIS }\end{array}$ & 2 & $0.9 \%$ & 14 & $6.2 \%$ & 47 & $20.7 \%$ & 111 & $48.9 \%$ & 53 & $23.3 \%$ \\
\hline $\begin{array}{l}\text { HAS ECONOMIC CRISIS CHANGED } \\
\text { YOUR JUDGMENT? }\end{array}$ & 5 & $2.2 \%$ & 19 & $8.4 \%$ & 40 & $17.6 \%$ & 121 & $53.3 \%$ & 42 & $18.5 \%$ \\
\hline $\begin{array}{c}\text { DO YOU BELIEVE THAT THE } \\
\text { STATE SUPPORTS HEALTH AS A } \\
\text { SOCIAL COMMODITY DURING } \\
\text { ECONOMIC CRISIS? }\end{array}$ & 75 & $33 \%$ & 111 & $48.9 \%$ & 32 & $14.1 \%$ & 9 & $4 \%$ & & \\
\hline
\end{tabular}

Table 3. Impact of Economic Crisis.

\begin{tabular}{|c|c|c|c|c|c|c|c|c|c|c|}
\hline \multirow{3}{*}{$\begin{array}{l}\text { REDUCTION IN NURSING } \\
\text { STAFF } \\
\text { INCREASED WORKLOAD }\end{array}$} & \multicolumn{2}{|c|}{ NOT AT ALL } & \multirow{2}{*}{\multicolumn{2}{|c|}{$\begin{array}{c}\text { A LITTLE BIT } \\
5825.6 \%\end{array}$}} & \multirow{2}{*}{\multicolumn{2}{|c|}{$\begin{array}{c}\text { MODERATELY } \\
6830 \%\end{array}$}} & \multirow{2}{*}{\multicolumn{2}{|c|}{$\begin{array}{l}\text { QUITE A BIT } \\
5323.3 \%\end{array}$}} & \multirow{2}{*}{\multicolumn{2}{|c|}{$\begin{array}{c}\text { EXTREMELY } \\
208.8 \%\end{array}$}} \\
\hline & \multirow{2}{*}{$\begin{array}{l}28 \\
6\end{array}$} & \multirow{2}{*}{$\begin{array}{l}12.3 \% \\
2.6 \%\end{array}$} & & & & & & & & \\
\hline & & & 17 & $7.5 \%$ & 63 & $27.8 \%$ & 111 & $48.9 \%$ & 30 & $13.2 \%$ \\
\hline PROLONGED WORKLOAD & 47 & $20.7 \%$ & 38 & $16.7 \%$ & 77 & $33.9 \%$ & 53 & $23.3 \%$ & 12 & $5.2 \%$ \\
\hline CUT WASTE & 2 & $0.9 \%$ & 11 & $4.8 \%$ & 55 & $24.2 \%$ & 99 & $43.6 \%$ & 59 & $26 \%$ \\
\hline $\begin{array}{l}\text { REDUCTION OF SURGICAL } \\
\text { PROCEDURES }\end{array}$ & 78 & $34.4 \%$ & 50 & $22 \%$ & 50 & $22 \%$ & 40 & $17.6 \%$ & 9 & $4 \%$ \\
\hline $\begin{array}{l}\text { REDUCTION OF COSTLY } \\
\text { SURGICAL PROCEDURES }\end{array}$ & 30 & $13.2 \%$ & 53 & $23.3 \%$ & 52 & $22.9 \%$ & 71 & $31.3 \%$ & 21 & $10.1 \%$ \\
\hline
\end{tabular}


did replace disposable material with multipurpose like fabric. One other result was that the patient satisfaction was moderately improved (52\%) and teamwork was also moderately improved (30\%). 42\% of the respondents answered that during the crisis there was not at all any technological equipment purchase when $36 \%$ believed that the maintenance of equipment kept moderately normal.

\section{Statistical Correlations}

A statistically significant correlation was found between gender of the respondents and how optimistic they were about economic crisis. It seemed that men OR Nurses were more optimistic than their female colleagues since $6.28 \%$ of men were moderately optimistic when at the same time their female colleagues were a little bit optimistic in $30.94 \%(\mathrm{p}=0.037)$ (Table 4).

Men also believe that patient satisfaction was quite a bit improved when $52.86 \%$ of women believe that patient satisfaction was only moderately improved $(p=0.02)$.

A statistically significant correlation was found between educational levels of the respondents and how stressed they were due to crisis. Diploma nurses seemed to be more stressed $(p=0.025)$ (Table 5).

The reduction on waste was better understood by RN nurses $(p=0.009)$ maybe because they are responsible for assessing those things and RN and Diploma nurses agree that quality of allocated materials has been decreased but RNs were surer about it $(\mathrm{p}=0.023)$.

Public hospitals because of staff reduction and private ones in lower degree because of public hospitals overloaded. The increased workload was followed by prolonged workload especially in public and army hospitals (p $=0.01$ ) due to different working terms/conditions. Even though the increased and prolonged workload and the decreased quality of allocated materials (equipment), mostly in public hospitals $(\mathrm{p}=0.00)$, the analysis saw that patient satisfaction was quite a bit increased by approximately $13 \%$ in public hospitals (a very optimistic result) $(p=0.001)$. One of the most important questions of the questionnaire was the last one where the respondents could describe measures their OR took in order to tackle economic crisis. The most important of all measures were teamwork to cope with less staff, effective central renderings in order to achieve better price without

Table 4. Chi-square correlation of gender and how optimistic they were about economic crisis.

\begin{tabular}{|c|c|c|c|c|c|c|c|}
\hline & & & \multicolumn{4}{|c|}{ OPTIMISTIC ABOUT ECONOMIC CRISIS } & \multirow{2}{*}{ p-value } \\
\hline & & & NOT AT ALL & A LITTLE BIT & MODERATELY & QUITE A BIT & \\
\hline \multirow{4}{*}{ GENDER } & & Count & 8 & 6 & 14 & 4 & \multirow{6}{*}{0.037} \\
\hline & ก & $\%$ of Total & $3.6 \%$ & $2.7 \%$ & $6.3 \%$ & $1.8 \%$ & \\
\hline & \multirow{2}{*}{ FEMALE } & Count & 42 & 69 & 55 & 24 & \\
\hline & & $\%$ of Total & $18.8 \%$ & $30.9 \%$ & $24.7 \%$ & $10.8 \%$ & \\
\hline \multirow{2}{*}{\multicolumn{2}{|c|}{ Total }} & Count & 50 & 75 & 69 & 28 & \\
\hline & & $\%$ of Total & $22.4 \%$ & $33.6 \%$ & $30.9 \%$ & $12.6 \%$ & \\
\hline
\end{tabular}

Table 5. Chi-square correlation of stress about economic crisis.

\begin{tabular}{|c|c|c|c|c|c|c|c|}
\hline \multirow{2}{*}{\multicolumn{2}{|c|}{ EDUCATIONAL LEVEL }} & \multicolumn{5}{|c|}{ DO YOU FEEL STRESS BECAUSE OF ECONOMIC CRISIS } & \multirow{2}{*}{ p-value } \\
\hline & & NOT AT ALL & A LITTLE BIT & MODERATELY & QUITE A BIT & EXTREMELY & \\
\hline \multirow{2}{*}{ REGISTERED NURSE } & Count & 1 & 12 & 39 & 81 & 30 & \multirow{6}{*}{0.025} \\
\hline & $\%$ of Total & $0.4 \%$ & $5.4 \%$ & $17.5 \%$ & $36.3 \%$ & $13.5 \%$ & \\
\hline \multirow{2}{*}{ NURSING ASSISTANTS } & Count & 1 & 2 & 6 & 30 & 21 & \\
\hline & $\%$ of Total & $0.4 \%$ & $.9 \%$ & $2.7 \%$ & $13.5 \%$ & $9.4 \%$ & \\
\hline \multirow{2}{*}{ Total } & Count & 2 & 14 & 45 & 111 & 51 & \\
\hline & $\%$ of Total & $0.9 \%$ & $6.3 \%$ & $20.2 \%$ & $49.8 \%$ & $22.9 \%$ & \\
\hline
\end{tabular}


reducing the quality, cut waste by educating nurses about supply prices (a wide variety of supply items are opened before asked in order to be ready to respond immediately to surgeon requests), shrink inventories lead to lower the risk of product expiration and obsolescence, trim preference cards because regularly updated cards do not include supplies that surgeons rarely use, watch costs so to standardize products as much as possible and last but not least to control supplies in order to reduce supply spending.

OR Nurses in private hospitals seemed to be more optimistic about the crisis $(\mathrm{p}=0.004)$ than their colleagues in public and army ones. This can be understood because of the salaries reductions in public and army hospitals on the time the study was conducted. On the other hand all hospitals had to deal with increased workload for different reasons $(\mathrm{p}=0.004)$ (Table 6).

\section{Discussion}

The findings of this study are in accordance with previous studies of researches who wrote about effective measures on how to grow revenue, control costs, and increase department profitability, in order to financially manage the OR which as everybody accepts is really a difficult task. Vendor management strategies would control supply costs since supplies may represent $50 \%$ or more of total costs per case. The supply management strategies that can yield positive results are to trim preference cards (cards that are not updated regularly often include supplies that surgeons rarely use), to cut waste (a wide variety of supply items are opened before asked in order to be ready to respond immediately to surgeon requests), to watch costs (standardize products as much as possible), shrink inventories (high inventory levels are expensive to maintain and increase the risk of product expiration and obsolescence) and finally establishing better control over low- and mid-priced supplies is a detail-intensive effort, but it can significantly reduce supply spending. As Simou \& Koutsogeorgou pointed out financial crisis could be considered also as a chance to address reforms in the health sector that will potentially lead to better access for patients and quality of healthcare, together with more incentives for health professionals to provide more efficient and less expensive healthcare services [10].

\section{Conclusion}

The results of the research from Greek OR reality reveal that we can continue providing quality care despite economic "storms". We can also "use" economic crisis to have an effective and efficient health system. We must understand that even the modest successful efforts can overall spend. Greek Nurses are optimistic and think despite staff reductions and increased and prolonged workload, measures taken sustains patient satisfaction from perioperative care. Although reducing supply costs is difficult, even a modestly successful effort can significantly cut overall spending.

\section{Limitations of the Study}

Due to its nature, the study was exposed to various factors such as the collection and compilation of the relevant

Table 6. Chi square correlation of optimism about economic crisis and type of hospital.

\begin{tabular}{|c|c|c|c|c|c|c|c|}
\hline \multirow{2}{*}{\multicolumn{2}{|c|}{ TYPE OF HOSPITAL }} & \multicolumn{5}{|c|}{ OPTIMISTIC ABOUT ECONOMIC CRISIS } & \multirow[b]{2}{*}{ p-value } \\
\hline & & $\begin{array}{l}\text { NOT AT } \\
\text { ALL }\end{array}$ & $\begin{array}{c}\text { A LITTLE } \\
\text { BIT }\end{array}$ & MODERATELY & $\begin{array}{l}\text { QUITE A } \\
\text { BIT }\end{array}$ & EXTREMELY & \\
\hline \multirow{2}{*}{$\begin{array}{l}\text { MILITARY } \\
\text { HOSPITAL }\end{array}$} & Count & 2 & 7 & 6 & 0 & 0 & \multirow{8}{*}{0.004} \\
\hline & $\%$ of Total & $0.9 \%$ & $3.1 \%$ & $2.7 \%$ & $0 \%$ & $0 \%$ & \\
\hline \multirow{2}{*}{$\begin{array}{c}\text { PUBLIC } \\
\text { HOSPITAL }\end{array}$} & Count & 38 & 62 & 48 & 15 & 1 & \\
\hline & \% of Total & $16.9 \%$ & $27.6 \%$ & $21.3 \%$ & $6.7 \%$ & $0.4 \%$ & \\
\hline \multirow{2}{*}{$\begin{array}{l}\text { PRIVATE } \\
\text { HOSPITAL }\end{array}$} & Count & 10 & 7 & 15 & 14 & 0 & \\
\hline & $\%$ of Total & $4.4 \%$ & $3.1 \%$ & $6.7 \%$ & $6.2 \%$ & $0 \%$ & \\
\hline \multirow{2}{*}{ Total } & Count & 50 & 76 & 69 & 29 & 1 & \\
\hline & $\%$ of Total & $22.2 \%$ & $33.8 \%$ & $30.7 \%$ & $12.9 \%$ & $0.4 \%$ & \\
\hline
\end{tabular}


data in a short term of one month and last minute adjustments.

Also another limitation has to do with the extent of study sample so the findings cannot be generalized beyond the studied cases.

\section{Implications for Practice, Research}

More research on how economic austerity affects ORs of National healthcare system should be made in order to address the problem

\section{References}

[1] Kentikelenis, A., Karanikolos, M., Reeves, A., McKee, M. and Stuckler, D. (2014) Greece’s Health Crisis: From Austerity to Denialism. The Lancet, 383,748-753. http://dx.doi.org/10.1016/s0140-6736(13)62291-6

[2] Kentikelenis, A., Karanikolos, M., Papanicolas, I., Basu, S., McKee, M. and Stuckler, D. (2011) Health Effects of Financial Crisis: Omens of a Greek Tragedy. The Lancet, 378, 1457-1458. http://dx.doi.org/10.1016/s0140-6736(11)61556-0

[3] Kiriopoulos, G. and Tsiandou, B. (2010) The Financial Crisis and Its Impact on Health and Medical Care. Archives of Hellenic Medicine, 27, 834-840.

[4] Fragkiadakis, G., Doumpos, M., Zopounidis, C. and Germain, C. (2013) Evaluation of the Efficiency of Greek Hospitals: A Non-Parametric Framework and Managerial Implications. Financial Engineering Laboratory, Technical University of Crete.

[5] Notara, V., Koulouridis, K., Violatyis, A. and Varga, E. (2013) Economic crisis and health. The role of health care professionals. Health Science Journal, 7, 149-154.

[6] Giokas, D. (2001) Greek Hospitals: How Well Their Resources Are Used. Omega, 29, 73-83. http://dx.doi.org/10.1016/S0305-0483(00)00031-1

[7] Economou, C. (2012) The Performance of the Greek Healthcare System and the Economic Adjustment Programme: "Economic Crisis” versus “System-Specific Deficits” Driven Reform. International Journal of Social Political Theory, 2, 33-68.

[8] Liaropoulos, L., Siskou, O., Kontodimopoulos, N., Kaitelidou, D., Lazarou, P., Spinthouri, M. and Tsavalias, K. (2012) Restructuring the Hospital Sector in Greece in Order to Improve Effectiveness and Efficiency. Koinonikisynoxikaianaptiksi, 7, 53-68.

[9] OR Manager Inc (2013) Taking Small Steps to Control Supply Costs Yields a Much Better Bottom Line. OR Manager, 28, $1-4$.

[10] Simou, E. and Koutsogeorgou, E. (2014) Effects of the Economic Crisis on Health and Healthcare in Greece in the Literature from 2009 to 2013: A Systematic Review. Health Policy, 115, 111-119. http://dx.doi.org/10.1016/j.healthpol.2014.02.002 